\author{
双链特异性核酸酶介导的高灵敏度 microRNA 分析 \\ 李晓利 ${ }^{a}$ 王愈聪 $*, a$ 张学晶 ${ }^{a}$ 赵云颕 ${ }^{a}$ \\ 刘成辉 $*, a, b$ 李正平 $a, b$ \\ ( ${ }^{a}$ 河北大学化学与环境科学学院 保定 071002) \\ $\left({ }^{b}\right.$ 陕西师范大学化学化工学院 西安 710062)
}

\begin{abstract}
摘要 基于氧化石墨烯(GO)对荧光标记单链 DNA 探针的荧光猝灭效应以及双链特异性核酸酶(DSN)选择性切割 DNA/RNA 杂合结构中 DNA 单链的特性, 本文建立了一种新型恒温信号放大方法用于 microRNA (miRNA) 的高灵敏度 检测. 靶标 miRNA 首先与荧光 DNA 探针杂交, DSN 能够特异性地将杂合双链中的 DNA 探针水解为碎片但不会降解 miRNA, GO 对酶切产生的宣核苷酸碎片吸附能力显著降低, 使得荧光基团远离 GO 表面而不被猝灭. 释放出的 miRNA 可再次发生与荧光 DNA 探针杂交.DSN 酶切等反应，如此反复，可实现恒温条件下一个 miRNA 分子与多个探针杂交、 酶切、释放荧光基团的循环过程，最终体系的苂光信号得到显著放大，通过记录体系的荧光信号即可实现对靶标 miRNA 的灵敏检测.

关键词 microRNA; 双链特异性核酸酶; 氧化石墨烯; 恒温信号扩增; 苂光
\end{abstract}

\title{
Double Strand-Specific Nuclease-Assisted Sensitive Detection of MicroRNA
}

\author{
Li, Xiaoli ${ }^{a} \quad$ Wang, Yucong*,a \\ Liu, Chenghui ${ }^{*}, a, b$ \\ Zhang, Xuejing ${ }^{a}$ \\ $\mathrm{Li}$, Zhengping ${ }^{a, b}$ \\ Zhao, Yunjie ${ }^{a}$ \\ $\left({ }^{a}\right.$ College of Chemistry and Environmental Science, Hebei University, Baoding 071002) \\ $\left({ }^{b}\right.$ School of Chemistry and Chemical Engineering, Shaanxi Normal University, Xi'an 710062)
}

\begin{abstract}
In this study, a new isothermal signal amplification method is developed for sensitive detection of microRNAs (miRNAs) by integrating the distinct advantages of graphene oxide (GO) for efficient fluorescence quenching of fluorophore-labeled single strand DNA (ssDNA) and double strand (ds)-specific nuclease (DSN) for highly selective digestion of DNA strand in DNA/RNA hybrids. DSN is a nuclease purified from hepatopancreas of Red King crab, which shows a strong preference for cleaving dsDNA and DNA in DNA/RNA hybrid duplexes. On contrast, DSN is practically inactive towards ssDNA or single- or double-stranded RNA. Herein, let-7a is selected as the proof-of-concept target miRNA and a fluorescein-labeled ssDNA probe is designed to be complementary to let-7a. The ssDNA probe, which will not be hydrolyzed by DSN in the absence of let-7a, will be adsorbed on GO via $\pi-\pi$ stacking, resulting in efficient fluorescence quenching. When let-7a is introduced, it will hybridize with the ssDNA probe to form a double helix structure (dsDNA). DSN can selectively cleave the DNA oligonucleotides of the DNA/RNA hybrid to produce very small DNA fragments. Let-7a is thus released and will hybridize with another ssDNA probe again, which will be further cleaved by DSN. In this manner, each let-7a molecule can specifically trigger various cycles of hybridization and DSN cleavage of fluorescent ssDNA to yield numerous small fragments of DNA oligonucleotides. It should be noted that the $\pi-\pi$ stacking interaction between GO and the very small DNA fragments bearing the fluorophores will be remarkably weakened, making the fluorescence maintained. Therefore, the DSN-mediated cycling of fluorescent ssDNA cleavage greatly amplifies the fluorescence signal for miRNA detection. Under the optimized experimental conditions, the fluorescence signal is proportional linearly to the concentration of let-7a in the range from $100 \mathrm{pmol} / \mathrm{L}$ to $5 \mathrm{nmol} / \mathrm{L}$, and the detection limit is calculated to be $60 \mathrm{pmol} / \mathrm{L}(3 \sigma)$. Furthermore, this proposed approach can also be applied to the simultaneous detection of multiplex miRNA targets.

Keywords microRNA; double strand-specific nuclease; graphene oxide; isothermal signal amplification; fluorescence
\end{abstract}

\section{1 引言}

MicroRNAs (miRNAs) 是一类生物体内普遍存在的 非编码单链小分子 RNA, 可通过与信使 RNA 结合来调 控靶基因的表达, 进而在动植物的生长、发育、分化和
生殖等过程中发挥重要的作用 ${ }^{[1]}$. 研究表明, 人类约 $30 \%$ 的基因受到 miRNA 的调控, miRNA 的表达水平与 人类多种疾病的发生密切相关 ${ }^{[2,3]}$, 因此, miRNA 的灵敏 检测对于深入理解其作用机制、疾病诊断以及基因药物

\footnotetext{
*E-mail: liuch@snnu.edu.cn; wangyucong@hbu.edu.cn; Tel.: 0312-5079403; Fax: 0312-5079403

Received January 4, 2014; published February 14, 2014.

Project supported by the National Natural Science Foundation of China (Nos. 21105020, 20905018) and financial support of Hebei University (No. 2009177). 项目受国家自然科学基金(Nos. 21105020, 20905018)及河北大学引进人才项目(No. 2009177)资助.
} 
的开发等方面都具有重要意义.

Northern 印迹法是当前 miRNA 分析的标准方法 ${ }^{[4,5]}$. 但该方法样品需求量大, 且存在操作繁琐、耗时长、干 扰因素多、易造成放射性污染等缺点. 微阵列芯片技 术 $^{[6,7]}$ 可实现多组分 miRNA 同时检测, 然而, 芯片的制 作和检测步骤繁琐且费用很高, 大大限制了其广泛使 用. 此外, 芯片上可利用的样品体积小, 发生交叉杂交 的几率较大. 近年来, 基于各种新型核酸扩增反应的 miRNA 分析方法得到了迅速发展, 被认为是显著提高 miRNA 检测灵敏度最有效的途径之一。例如，基于反转 录聚合酶链式反应 $(\mathrm{RT}-\mathrm{PCR})^{[8]}$ 、滚环扩增技术 $(\mathrm{RCA})^{[9,10]}$ 、连接链式反应 $(\mathrm{LCR})^{[11]}$ 及多种恒温扩增技 术 ${ }^{[12,13]}$ 相继被应用于 miRNA 分析. 这些方法在灵敏度 和特异性方面都得到了很大的提高, 但是由于 miRNA 序列很短, 这些扩增手段及相应的探针设计都需要非常 精细和复杂的设计. 因此, 发展设计简单、造价低廉、 灵敏度高和特异性好的 miRNA 检测方法依然是该领域 研究的热点.

最近, 基于氧化石墨烯 $(\mathrm{GO})$ 等新型碳材料的苂光 传感平台在核酸分析方面的应用吸引了研究者广泛的 兴趣 ${ }^{[14 ~ 20]}$. GO 是一种二维单分子层碳材料, 可通过 $\pi-\pi$ 堆积效应强烈吸附单链寡核苷酸分子, 并高效猝灭寡核 苷酸上标记的苂光染料或苂光纳米粒子的苂光信号. 若 加入与该寡核苷酸探针互补的核酸分子, 二者杂交形成 的双链核酸结构在 GO 表面的吸附能力会显著降低，从 而离开 GO 表面使荧光信号得以恢复 ${ }^{[14,15]}$. 基于此原理, Yang 等 ${ }^{[14]}$ 率先将基于 GO 的荧光传感策略用于特定序 列 DNA 的检测. 在此基础上, Fan 研究组 ${ }^{[19]}$ 采用 GO 和 多色荧光标记技术, 实现了多靶标 DNA 分子的同时分 析. Zhang 等 ${ }^{[21]}$ 进一步将该策略应用到了 miRNA 分析 中，建立了一种检测 miRNA 的简便方法. 这类基于 GO 的新颖核酸分析方法简单、快捷，而且适用于多靶标分 子同时检测，展现出了很好的应用前景. 但是每个靶标 分子只能与 GO 表面吸附的一条苂光寡核苷酸探针杂交 而恢复单个苂光基团的信号，导致灵敏度较低，对核酸 分子的检出限多在 $\mathrm{nM}$ 量级. 因此如何进一步提高基于 $\mathrm{GO}$ 的核酸分析方法的灵敏度, 是拓展该类方法应用范 围的关键.

双链特异性核酸酶(duplex-specific nuclease, DSN), 是一种从堪察加拟石蟹的肝胰腺中分离得到的核酸 酶 $^{[22], D S N}$ 能够高选择性地识别并切割完全匹配的 DNA 双链或者 RNA/DNA 杂交双链中的 DNA，对单链 DNA、RNA 或者双链 RNA 没有作用，且能够很好地区 分单碱基错配 ${ }^{[23]}$. 基于 DSN 酶优异的选择性酶切能力, $\mathrm{Ye}^{[24]}$ 和 $\mathrm{Yang}^{[25]}$ 课题组分别结合分子信标技术, 将 DSN 酶创新性地用于 miRNA 分析领域. 本论文中, 我们结 合 GO 对荧光标记单链 DNA 探针的菼光猝灭效应以及 DSN 选择性切割 DNA/RNA 杂合结构中 DNA 单链的特
性，提出了一种设计简单的恒温信号放大策略用于 miRNA 的高灵敏度检测.

\section{2 结果与讨论}

\section{1 检测原理}

本文所提出的 miRNA 检测方法原理如图 1 所示. 首先，针对靶标 miRNA 序列，设计与之序列互补的荧 光标记的单链 DNA 探针. 由于 DSN 对单链核酸无识别 及酶切作用, 因此体系中无 miRNA 靶标时, 荧光 DNA 探针由于 $\pi-\pi$ 堆积效应而吸附在 $\mathrm{GO}$ 表面，导致其荧光 信号被 GO 完全猝灭. 当体系中加入靶标 miRNA 时, 荧 光 DNA 探针与 miRNA 靶标杂交形成完全匹配的 DNA/RNA 双螺旋结构, 进而 DSN 选择性地将双链结构 中的苂光 DNA 探针水解为碎片. GO 对酶切产生的寡核 苷酸碎片吸附能力显著降低，使得荧光基团远离 GO 表 面而保持固有的苂光性能. 该过程中 DSN 不会降解双 螺旋结构中的 miRNA 从而使其被释放出来, 可再次发 生与荧光 DNA 探针杂交、DSN 酶切等反应，如此循环 反复, 可实现恒温条件下一个 miRNA 分子与多个探针 杂交、酶切、释放荧光基团的循环过程，最终体系的荧 光信号得到显著放大, 通过记录体系的荧光信号即可实 现对 miRNA 的灵敏检测.

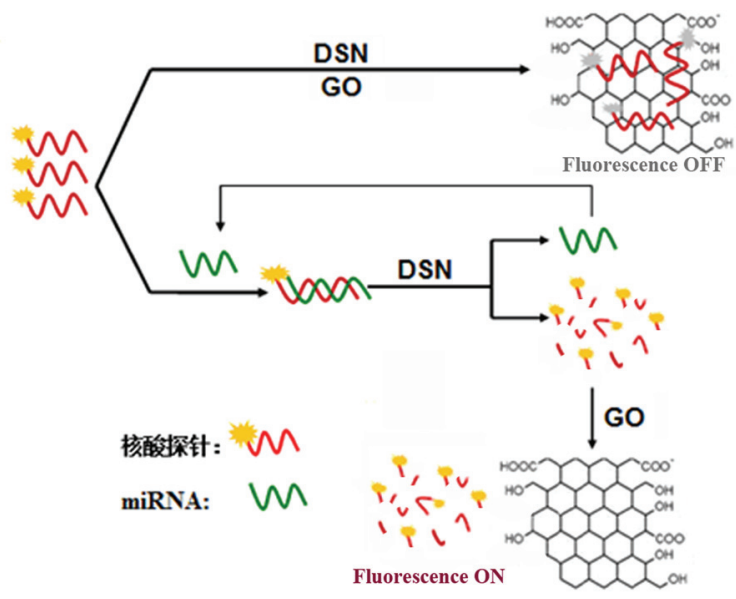

图 1 DSN 酶切信号放大体系检测 miRNA 原理图

Figure 1 Schematic illustration of the DSN-assisted signal amplification approach for detection of miRNA

\section{2 方案可行性验证}

我们对上述设计方案是否可行进行了实验验证. 选 取 let-7a 为靶标 miRNA 分子并合成了与 let-7a 完全互补 的苂光素标记的 DNA 探针 (FAM-DNA). 首先优化了体 系中 GO 的用量. 如图 2a 所示, 在固定的 FAM-DNA 浓 度下，随着 $\mathrm{GO}$ 用量的增加，吸附到 $\mathrm{GO}$ 表面的 FAM-DNA 逐渐增多，相应的荧光信号逐渐降低，当 $\mathrm{GO}$ 浓度大于 $0.8 \mu \mathrm{g} / \mathrm{mL}$ 时, FAM-DNA 的苂光信号被完 全猝灭, 为了保证较低的背景干扰, 本实验中选取 GO 用量为 $1.0 \mu \mathrm{g} / \mathrm{mL}$. 
从图 $2 \mathrm{~b}$ 结果可看出, 在优化的 GO 用量下, FAMDNA 的苂光信号完全猝灭. 若首先加入一定量的 let-7a 使其与 FAM-DNA 杂交, 再加入 GO 后杂交形成的双链 结构在 GO 表面的吸附作用明显减弱, 使体系的荧光得 到了一定程度的恢复. 与之对比, 如果在加入 let-7a 的 同时加入 DSN, let-7a 在 DSN 介导下循环与 FAM-DNA 杂交、酶切, 形成的苂光 DNA 微小片段与 GO 结合能 力显著减弱, 使体系的菼光信号得到了显著放大. 如图 2 所示, 相同的 miRNA 浓度下, 经过 DSN 介导的循环 放大反应体系产生的荧光信号要远远高于未加 DSN 体 系的信号, 而二者空白信号几乎相等. 这一结果充分证 明 DSN 酶对单链 FAM-DNA 无水解作用, 而在 let-7a 存在时会显著增强体系荧光强度, 表明我们提出的设计 方案是可行的, 能够有效改善 let-7a 的检测灵敏度.
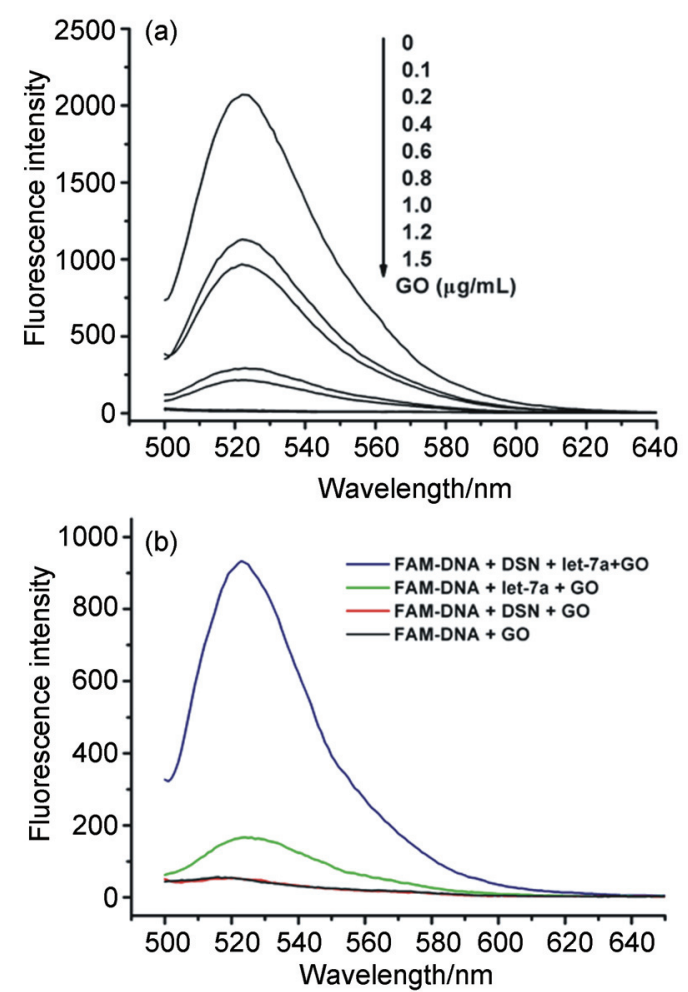

图 2 (a) GO 用量的优化, FAM-DNA 浓度固定为 $50 \mathrm{nmol} / \mathrm{L}$; (b)不同 组分存在时体系的荧光光谱图, FAM-DNA: $50 \mathrm{nmol} / \mathrm{L} ; \mathrm{GO}: 1.0$ $\mu \mathrm{g} / \mathrm{mL}$; let-7a: $15 \mathrm{nmol} / \mathrm{L}$; DSN: $0.2 \mathrm{U}$; $T: 52{ }^{\circ} \mathrm{C}$

Figure 2 (a) Optimization of $\mathrm{GO}$ concentration for fluorescence quenching of FAM-DNA $(50 \mathrm{nmol} / \mathrm{L})$; (b) fluorescence spectra of the GO-based system in the presence of different components.

\subsection{DSN 信号放大体系反应条件的优化}

该反应体系受温度的影响比较大, 因此我们首先对 反应温度进行了优化. 根据产品说明, DSN 在 $45 \sim 65{ }^{\circ} \mathrm{C}$ 之间能保持较高活性, 温度过高或过低都会使其活性明 显降低. 此外, 除了考虑 DSN 本身对温度的要求外, 还 要综合考虑 DNA 探针和 let-7a 杂合双链结构的熔链温 度 $\left(T_{\mathrm{m}}\right.$ 值), 因为反应温度达到或高于 $T_{\mathrm{m}}$ 值时不利于双
链结构的生成从而无法形成有效的杂交-DSN 酶切循环 放大过程. 本文中, let-7a 和 FAM-DNA 在反应介质中的 $T_{\mathrm{m}}$ 值约为 $57{ }^{\circ} \mathrm{C}$ 左右, 因此我们主要考察了低于 $T_{\mathrm{m}}$ 值的 $47,50,52$ 和 $55^{\circ} \mathrm{C}$ 对实验结果的影响, 结果如图 3 所示. 当温度较低时, 空白体系(不加 let-7a)的信号较高, 可能 是由于 FAM-DNA 探针在温度较低时存在随机碱基匹 配形成的二级结构, 能被 DSN 识别并水解, 导致空白信 号增加. 随着反应温度的升高, FAM-DNA 形成随机双 链结构的几率降低, 因此空白信号一直呈降低趋势. 同 时，体系中存在 let-7a 时，随着反应体系温度的逐渐升 高, DSN 酶切效率升高, 使检测信号有所增加. 但是, 当温度达到 $55{ }^{\circ} \mathrm{C}$ 后, 样品体系信号急剧下降, 这可能 是由于 $55{ }^{\circ} \mathrm{C}$ 与 $T_{\mathrm{m}}$ 值已经十分接近, 导致酶切效果显著 降低. 图 $3 \mathrm{~b}$ 为不同温度条件下相同浓度 let-7a 产生的荧 光信号与空白体系信号的比值, 可以看出当反应温度为 $52{ }^{\circ} \mathrm{C}$ 时, 反应体系的信噪比达到了最大值, 因此确定最 佳反应温度为 $52{ }^{\circ} \mathrm{C}$.
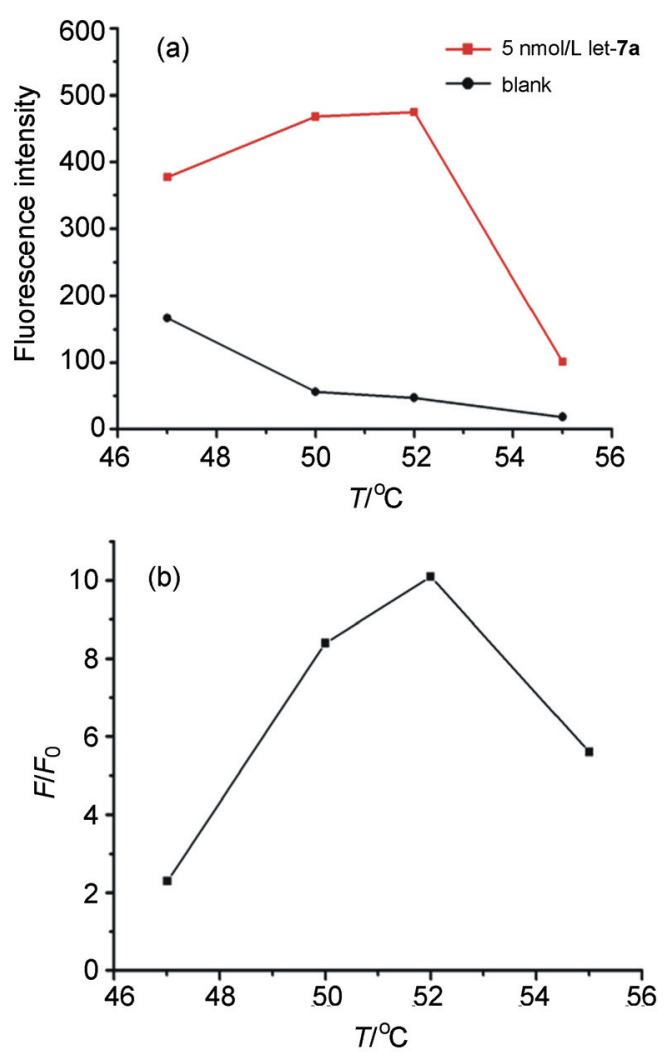

图 3 反应温度对 miRNA 检测体系荧光信号的影响. 苂光强度为 523 $\mathrm{nm}$ 处的峰值信号; $F$ 为 $5 \mathrm{nmol} / \mathrm{L}$ let-7a 产生的荧光响应而 $F_{0}$ 为未加入 let-7a 的空白对照体系的苂光响应. 其它条件: FAM-DNA: $50 \mathrm{nmol} / \mathrm{L}$; GO: $1.0 \mu \mathrm{g} / \mathrm{mL}$; DSN: $0.2 \mathrm{U}$

Figure 3 Optimization of reaction temperature of the proposed miRNA assay

此外, FAM-DNA 探针的循环酶切放大效率与 DSN 的用量密切相关, 因此 miRNA 的检测灵敏度必然会受 到体系中酶含量的影响. 本实验在 let-7a 浓度为 5 $\mathrm{nmol} / \mathrm{L}$ 时，分别考察了不同浓度的 DSN 对体系荧光响 
应信号的影响, 未加 let-7a 的空白体系作为对照. 从图 $4 \mathrm{a}$ 可以看出, 随着酶用量的增大, 样品信号先快速增 加, 然后保持相对平稳的趋势, 与此同时空白信号虽有 微弱升高但是变化并不大. 当酶用量为 $0.2 \mathrm{U}$ 时, 样品 和空白信号的比值达到最大值(图 4b), 因此本实验中选 择 $0.2 \mathrm{U}$ 为最佳 DSN 用量.
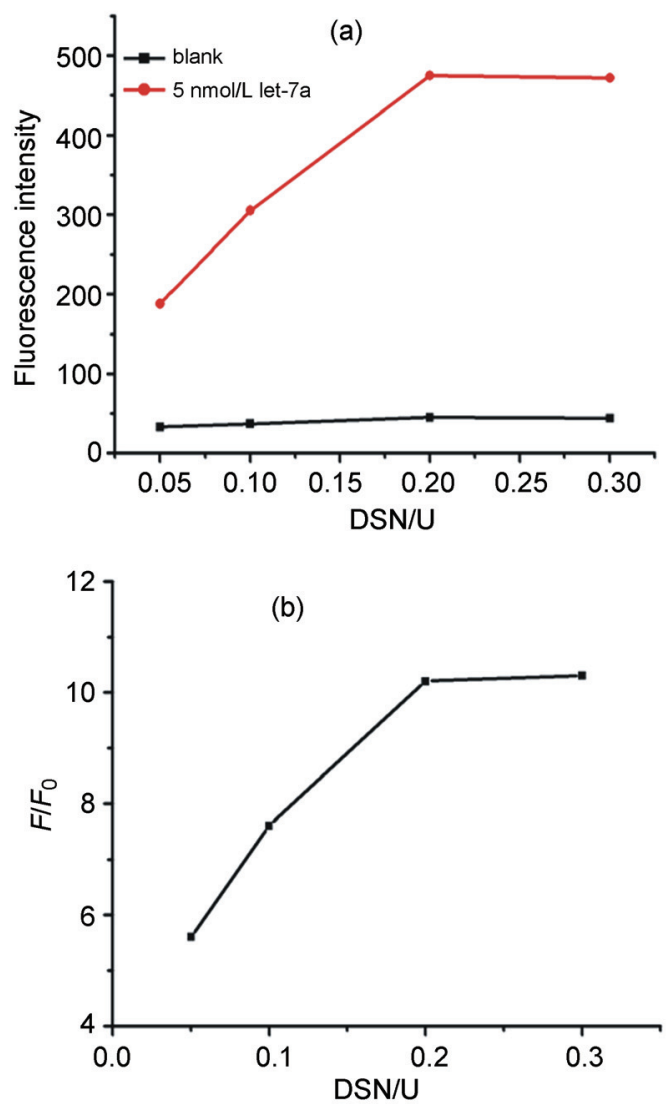

图 4 DSN 用量对 miRNA 检测体系荧光信号 $(523 \mathrm{~nm})$ 的影响. FAM-DNA: $50 \mathrm{nmol} / \mathrm{L} ; \mathrm{GO}: 1.0 \mu \mathrm{g} / \mathrm{mL}$; 反应温度: $52{ }^{\circ} \mathrm{C}$

Figure 4 Effect of DSN amount on the proposed miRNA assay.

\subsection{Let-7a 分析结果}

在上述优化条件下, 本文所提出的方法对 let-7a 检 测结果如图 5 所示. 从图中可看到, 随着 let-7a浓度的逐 渐增加, 体系的荧光信号逐渐增强. 并且, 体系的苂光 信号与 let-7a 浓度在 $100 \mathrm{pmol} / \mathrm{L}$ 到 $5 \mathrm{nmol} / \mathrm{L}$ 之间呈良好 的线性关系, 线性方程为 $\Delta F=0.0819 C+10.27\left(R^{2}=\right.$ $0.9983)$, 其中 $\Delta F$ 表示 let-7a 产生的荧光信号(523 nm) 扣除空白体系的信号值, $C$ 单位为 $\mathrm{pmol} / \mathrm{L}$. 通过计算可 得 let-7a 的检出限为 $60 \mathrm{pmol} / \mathrm{L}(3 \sigma, n=11)$.

我们同时进行了如下对比实验来证明本文方法中 DSN 对提高 let-7a 检测灵敏度的重要作用. 在对比实验 中不加入 DSN 酶, 仅仅依靠 let-7a 与 FAM-DNA 杂交形 成的双链结构不会被 GO 吸附并猝灭, 从而通过记录体 系荧光信号实现 let-7a 定量检测. 由于每个 let-7a 只能与 单一的 FAM-DNA 杂交并恢复其苂光, 因此, 只有在较
高 let-7a 浓度时体系才有较明显的荧光信号. 实验结果 表明，该对比方法最低只能检测到 $5 \mathrm{nmol} / \mathrm{L}$ 的 let-7a. Zhang 等 ${ }^{[21]}$ 最近的报道也表明, 采用类似的直接杂交结 合 $\mathrm{GO}$ 荧光猝灭技术，最低只能检测到约 $50 \mathrm{nmol} / \mathrm{L}$ 的 靶标 mir-21. 该结果清楚表明将我们提出的 DSN 循环 放大策略与常规 GO 荧光传感平台相结合可显著提高 miRNA 检测灵敏度，与未使用 DSN 酶的测定结果相比， 灵敏度提高了约两个数量级.
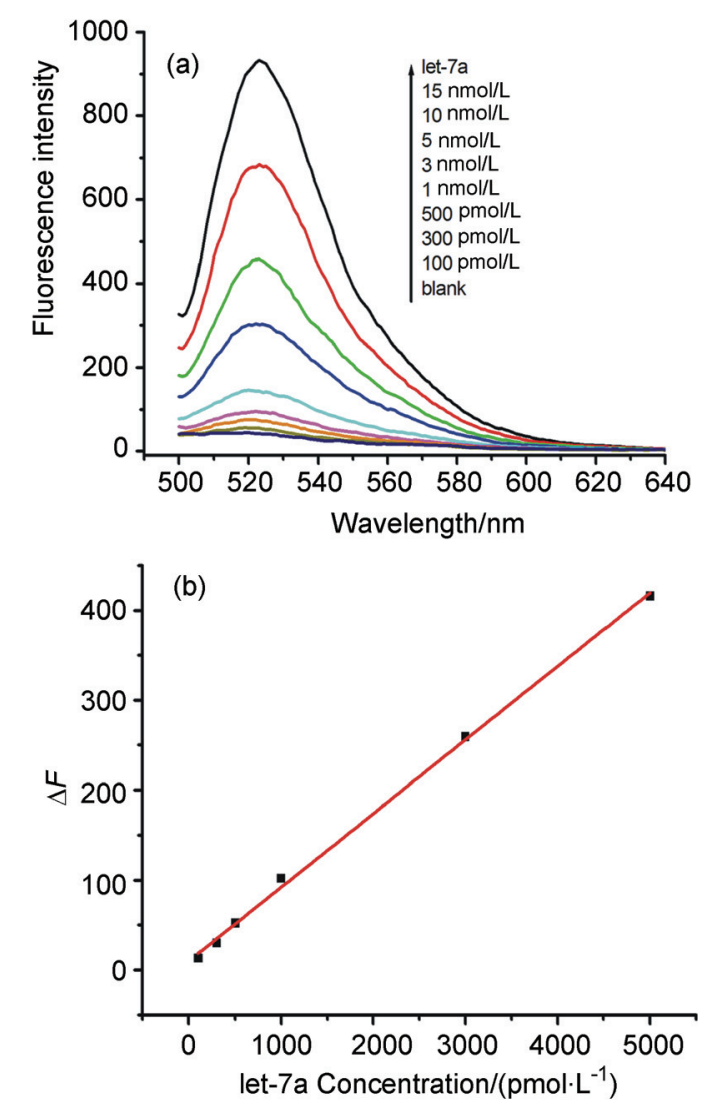

图 5 (a)不同浓度 let-7a 时检测体系的苂光光谱图; (b) $523 \mathrm{~nm}$ 处苂光 强度值与 let-7a 浓度的关系图. FAM-DNA: $50 \mathrm{nmol} / \mathrm{L} ; \mathrm{GO}: 1.0 \mu \mathrm{g} / \mathrm{mL}$; DSN: $0.2 \mathrm{U}$; 温度: $52{ }^{\circ} \mathrm{C}$

Figure 5 (a) Fluorescence spectra of the proposed assay in the presence of different concentrations of let-7a; (b) plot between the fluorescence intensity at $523 \mathrm{~nm}$ and the let- 7 a concentration.

\section{5 方法的特异性评价}

为验证本文方法的特异性, 我们考察了 $\mathrm{mir}-21$, mir-143 以及同为 let-7 家族成员的 let-7c, let-7d 对 let-7a 检测的干扰情况. 如图 6 所示, 采用 let-7a 特异性的 FAM-DNA 探针，在相同实验条件下，只有 let-7a 产生 了显著的苂光信号, 而非同家族的 mir-143 和 mir-21 未 产生明显荧光响应，表明该方法具有很好的特异性. 另 外, 众所周知, let-7a 所属的 let-7家族成员之间的序列非 常相近，彼此只相差一个或几个碱基，因此能否区分 let-7 家族是评判 miRNA 检测方法特异性好坏的重要指 标. 从图 6 结果可看出, 与 mir-143 和 mir-21 相比, 序列 
相似性高的 let-7 家族成员对 let-7a 检测的干扰程度明显 增大, 这是由于 let-7c 和 let-7d 与 let- $7 \mathrm{a}$ 序列相比只存在 一个和三个碱基的差别, 因此 let-7c 和 let-7d 也可与荧 光 DNA 探针发生非特异性杂交反应而产生干扰信号. 但从图中结果可看出, let-7a 产生的强荧光响应与 let-7c 和 let-7d 产生的干扰信号能够显著区分开, 表明该方法 具有区分单碱基差异的能力. 综上所述, 本论文所建立 的实验方法选择性比较好, 可以实现对目标分子 miRNA 的特异性检测.

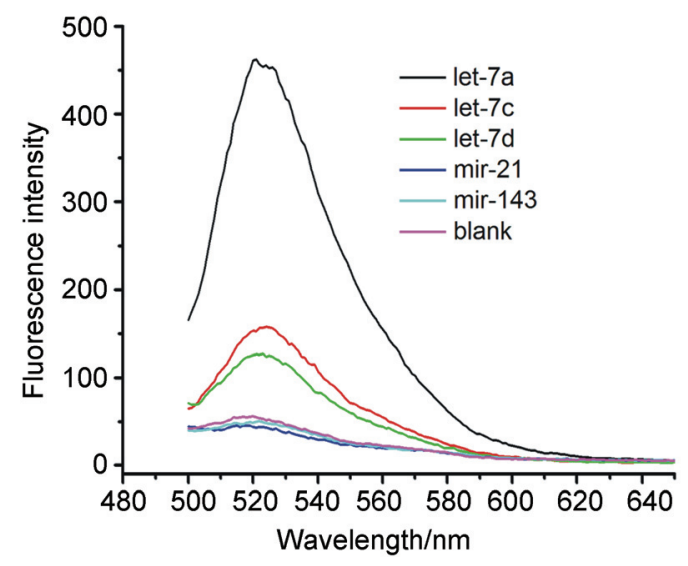

图 6 本文方法的选择性评价. 所有 miRNA (mir-21, mir-143, let-7c, let-7d 和 let-7a) 浓度均为 $5 \mathrm{nmol} / \mathrm{L}$; 其他条件同图 5

Figure 6 Specificity evaluation of the proposed miRNA assay. The concentrations of all the miRNAs are fixed at $5 \mathrm{nmol} / \mathrm{L}$ for this study

\section{6 在多重 miRNA 检测中的应用}

MiRNA 对于生命过程的调控, 往往是多种 miRNA 分子共同作用的结果, 因此基于 miRNA 的疾病诊断往 往需要同时对多个目标 miRNA 分子 $(2 \sim 15$ 个)进行检 测 $^{[26 ~ 28]}$. 由于 $G O$ 对单链 DNA 的吸附能力主要是基于 $\pi-\pi$ 堆积作用, 其吸附能力对 DNA 序列并无特殊要求. 此外, GO 对多种发射波长的荧光染料均具有较好的猝 灭作用，因此针对不同 miRNA 靶标分子设计其对应的 互补 DNA 探针, 每种探针上修饰特定发射波长的荧光 分子，本文提出的基于 DSN 酶切信号放大的技术有望 用于多目标 miRNA 的同时检测. 我们以 let-7a 和 mir-143 的同时检测为模型对此进行了实验验证. FAM-DNA 和 TMR-DNA-143 分别作为与 let-7a 和 mir-143 完全匹配的单链 DNA 探针, 其上分别标记上荧 光素(FAM)和罗丹明(TMR)苂光染料, 对应的发射波长 分别在 523 和 $580 \mathrm{~nm}$. 将两种探针及 DSN 混合, 依照本 文建立的方法, 我们对不同的样品进行了检测, 结果如 图 8 所示. 若样品中两种 miRNA 均不存在, FAM 和 TMR 苂光信号都能被 GO 高效地猝灭. 当只加入 let-7a 时只有 $523 \mathrm{~nm}$ 处产生强的荧光而只加入 mir-143 时, 仅 在 $580 \mathrm{~nm}$ 检测到较强的响应信号; 当同时加入 let-7a 和 mir-143 时, 在 523 和 $580 \mathrm{~nm}$ 波长处均可得到较强的苂 光信号. 这一结果充分证明我们所建立的方法在多重
miRNA 检测方面具有较好的应用前景.

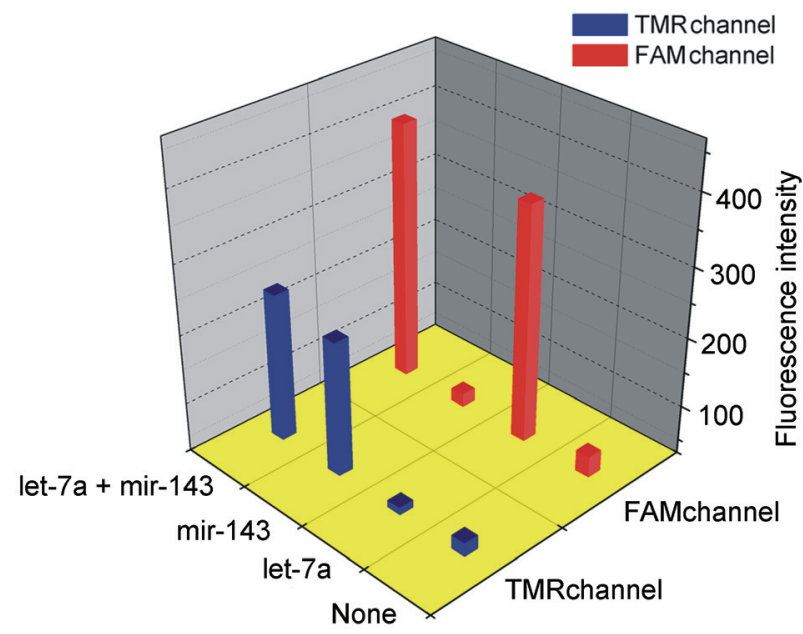

图 7 该方法用于 let-7a 和 mir-143 同时检测的分析结果. Let-7a 特异 性探针 FAM-DNA 及 mir-143 特异性探针 TMR-DNA-143 浓度均为 50 $\mathrm{nmol} / \mathrm{L}$, let- $7 \mathrm{a}$ 和 mir-143 所用浓度均为 $5 \mathrm{nmol} / \mathrm{L}$; GO: $2 \mu \mathrm{g} / \mathrm{mL}$

Figure 7 Application of the proposed assay for simultaneous detection of let-7a and mir-143

\section{3 结论}

基于 GO 对不同存在形态下核酸探针标记的荧光基 才猝灭能力的显著差别，以及 DSN 选择性切割 DNA/RNA 杂合结构中 DNA 单链的特性, 本文建立了 一种灵敏检测 miRNA 的新型信号放大方法. 该方法恒 温进行，设计简单，灵敏度高，与基于 $\mathrm{GO}$ 的常规核酸 苂光传感方法相比, DSN 的循环酶切放大效应使本方法 灵敏度提高了约两个数量级. 此外, 通过多荧光标记技 术，该方法还可用于多种 miRNA 的同时检测，在基于 miRNA 分析的疾病诊断方面展现出了良好应用前景.

\section{4 实验部分}

\section{1 试剂与仪器}

HPLC 纯化的 DNA 购自上海生工生物技术有限公 司; 特异性双链核酸酶(DSN), 购自 Evrogen (Moscow, Russia); HPLC 纯化的 RNA, RNA 酶抑制剂以及 DEPC 水都购自于大连宝生物工程有限公司; 其他试剂均为分 析纯．氧化石墨烯(GO)根据 Hummers 法制得 ${ }^{[16,29]}$. 本实 验所有荧光光谱均由 F-4500 型苂光分光光度计(Hitachi, Japan)测得.

本文用到的 DNA 和 RNA 序列如下:

FAM-DNA:

5'(FAM)-AACTATACAACCTACTACCTCA-3'

TMR-DNA-143:

5'(TMR)-GAGCTACAGTGCTTCATCTCA-3'

let-7a: 5'-UGAGGUAGUAGGUUGUAUAGUU-3'

let-7c: 5'-UGAGGUAGUAGGUUGUAUGGUU-3'

let-7d: 5'-AGAGGUAGUAGGUUGCAUAGU-3' 


\section{mir-21: 5'-UAGCUUAUCAGACUGAUGUUGA-3' mir-143: 5'-UGAGAUGAAGCACUGUAGCUC-3'}

\section{$4.2 \operatorname{miRNA}$ 的检测步骤}

以 let-7a 的检测为例简述一下本文方法的操作流程. 终浓度为 $50 \mathrm{nmol} / \mathrm{L}$ 的 FAM-DNA 探针, $0.2 \mathrm{U} \mathrm{DSN,} 10 \mathrm{U}$ RNA 抑制酶以及不同浓度的 let-7a 加入到 DSN 反应缓 冲溶液中 $\left(50 \mathrm{mmol} / \mathrm{L}\right.$ Tris- $\mathrm{HCl}, \mathrm{pH} 8.0 ; 5 \mathrm{mmol} / \mathrm{L} \mathrm{MgCl}_{2}$; $1 \mathrm{mmol} / \mathrm{L} \mathrm{DTT}$ )置于 $52{ }^{\circ} \mathrm{C}$ 反应 $4 \mathrm{~h}$. 之后加入一定量的 EDTA 使 DSN 失活并加入 $1.0 \mu \mathrm{g} / \mathrm{mL}$ 的 GO, 使最终体 积为 $200 \mu \mathrm{L}$. 室温放置 $40 \mathrm{~min}$ 之后, 在 $480 \mathrm{~nm}$ 的激发 波长下, 进行苂光光谱扫描并记录最大发射波长处的荧 光强度.

\section{References}

[1] Carrington, J. C.; Ambros, V. Science 2003, 301, 336

[2] Lewis, B. P.; Burge, C. B.; Bartel, D. P. Cell 2005, 120, 15.

[3] Dong, H. F.; Lei, J. P.; Ding, L.; Wen, Y. Q.; Ju, H. X.; Zhang, X. J. Chem. Rev. 2013, 113, 6207.

[4] Calin, G. A.; Dumitru, C. D.; Shimizu, M.; Bichi, R.; Zupo, S.; Noch, E.; Aldler, H.; Rattan, S.; Keating, M.; Rai, K.; Rassenti, L.; Kipps, T.; Negrini, M.; Bullrich, F.; Croce, C. M. Proc. Natl. Acad. Sci. 2002, 99, 15524

[5] Lagos-Quintana, M.; Rauhut, R.; Lendeckel, W.; Tuschl, T. Science 2001, 294, 853.

[6] Liu, C. G.; Calin, G. A.; Meloon, B.; Gamliel, N.; Sevignani, C.; Ferracin, M.; Dumitru, C. D.; Shimizu, M.; Zupo, S.; Dono, M.; Alder, H.; Bullrich, F.; Negrini, M.; Croce, C. M. Proc. Natl. Acad. Sci. 2004, 101, 9740.

[7] Thomson, J. M.; Parker, J.; Perou, C. M.; Hammond, S. M. Nat. Methods 2004, 1, 47.

[8] Raymond, C. K.; Roberts, B. S.; Garrett-Engele, P.; Lim, L. P.; Johnson, J. M. RNA 2005, 11, 1737.

[9] Jonstrup, S. P.; Koch, J.; Kjems, J. RNA 2006, 12, 1747.

[10] Cheng, Y. Q.; Zhang, X.; Li, Z. P.; Jiao, X. X.; Wang, Y. C.; Zhang,
Y. L. Angew. Chem., Int. Ed. 2009, 48, 3268.

[11] Yan, J. L.; Li, Z. P.; Liu, C. H.; Cheng, Y. Q. Chem. Commun. 2010, 46, 2432.

[12] Jia, H. X.; Li, Z. P.; Liu, C. H.; Cheng, Y. Q. Angew. Chem., Int. Ed. 2010, 49, 5498 .

[13] Li, C. P.; Li, Z. P.; Jia, H. X.; Yan, J. L. Chem. Commun. 2011, 47, 2595.

[14] Lu, C. H.; Yang, H. H.; Zhu, C. L.; Chen, X.; Chen, G. N. Angew. Chem., Int. Ed. 2009, 48, 4785.

[15] Liu, B. W.; Sun, Z. Y.; Zhang, X.; Liu, J. W. Anal. Chem. 2013, 85, 7987.

[16] Yang, L.; Liu, C. H.; Ren, W.; Li, Z. P. ACS Appl. Mater. Interfaces 2012, 4, 6450 .

[17] He, Y.; Huang, G. M.; Cui, H. ACS Appl. Mater. Interfaces 2013, 5, 11336.

[18] Li, F.; Huang, Y.; Yang, Q.; Zhong, Z. T.; Li, D.; Wang, L. H.; Song, S. P.; Fan, C. H. Nanoscale 2010, 2, 1021.

[19] He, S.; Song, B.; Li, D.; Zhu, C.; Qi, W.; Wen, Y.; Wang, L.; Song, S.; Fan, C. Adv. Funct. Mater. 2010, 20, 453.

[20] Yang, F.; Wang, L.; Guo, Z. Acta Chim. Sinica 2012, 70, 1283. (杨 帆, 王伶俐, 郭志慧, 化学学报, 2012, 70, 1283.)

[21] Lu, Z. X.; Zhang, L. M.; Deng, Y.; Li, S.; He, N. Y. Nanoscale 2012, 4, 5840 .

[22] Anisimova, V. E.; Rebrikov, D. V.; Shagin, D. A. BMC Biochemistry 2008, 9, 14.

[23] Shagin, D. A.; Rebrikov, D. V.; Kozhemyako, V. B.; Altshuler, I. M.; Shcheglov, A. S.; Zhulidov, P. A.; Bogdanova, E. A.; Staroverov, D. B.; Rasskazov, V. A.; Lukyanov, S. Genome Res. 2002, 12, 1935 .

[24] Yin, B. C.; Liu, Y. Q.; Ye, B. C. J. Am. Chem. Soc. 2012, 134, 5064.

[25] Lin, X. Y.; Zhang, C.; Huang, Y. S.; Zhu, Z.; Chen, X.; Yang, C. Y. Chem. Commun. 2013, 49, 7243.

[26] Iorio, M. V.; Ferracin, M.; Liu, C. G.; Veronese, A.; Spizzo, R.; Sabbioni, S.; Magri, E.; Pedriali, M.; Fabbri, M.; Campiglio, M. Ménard, S.; Palazzo, J. P.; Rosenberg, A.; Musiani, P.; Volinia, S.; Nenci, I.; Calin, G. A.; Querzoli, P.; Negrini, M.; Croce, C. M. Cancer Res. 2005, 65, 7065.

[27] Wegman, D. W.; Cherney, L. T.; Yousef, G. M.; Krylov, S. N. Anal. Chem. 2013, 85, 6518.

[28] Zhang, P. B.; Zhang, J. Y.; Wang, C. L.; Liu, C. H.; Wang, H.; Li, Z. P. Anal. Chem. 2014, 86, 1076.

[29] Hummers, W. S.; Offeman, R. E. J. Am. Chem. Soc. 1958, 80, 1339. 